\title{
Pembrolizumab in Combination with Axitinib as First-Line Treatment for Patients with Renal Cell Carcinoma (RCC): Evidence to Date
}

This article was published in the following Dove Press journal: Cancer Management and Research

\section{Vincent Chau (iD \\ Marijo Bilusic (D)}

Genitourinary Malignancies Branch, Center for Cancer Research, National Cancer Institute, National Institutes of Health, Bethesda, Maryland, USA
Correspondence: Marijo Bilusic

Tel + I-30I-765-4457

$\mathrm{Fax}+|-240-54|-4548$

Email marijo.bilusic@nih.gov

\begin{abstract}
Over the last 18 months, 3 immunotherapy combination regimens (ipilimumab + nivolumab, pembrolizumab + axitinib, and axitinib + avelumab) were approved by the US Food and Drug Administration for the first-line treatment of metastatic renal cell carcinoma (mRCC), making selection of the optimal first-line treatment regimen very challenging. As of April 2020, preferred first-line treatment options for $\mathrm{mRCC}$ are pembrolizumab + axitinib and ipilimumab + nivolumab, based on the improvement in overall survival and progression-free survival compared to sunitinib, as observed in pivotal phase III clinical trials. Because the combination of 2 drugs is typically more toxic than a monotherapy, careful attention must be given to overlapping toxicities. The pembrolizumab + axitinib combination led to grade $\geq 3$ adverse events in $75.8 \%$ of patients (vs $70.6 \%$ in the sunitinib group), while grade $\geq 3$ adverse events were less frequent in the nivolumab + ipilimumab group compared to the sunitinib group. Discontinuation rates due to toxicity were $10.7 \%$ for pembrolizumab + axitinib (both drugs), $22 \%$ for ipilimumab + nivolumab and were comparable with sunitinib in both studies (13.9\% and $12 \%$, respectively). The combination of pembrolizumab + axitinib may have immune-modulating functions that may provide clinical benefit without the additional toxicity observed with ipilimumab + nivolumab. In addition, this tyrosine kinase inhibitor + immune checkpoint combination should have faster treatment response in patients with larger disease burden or in more symptomatic patients, which makes this combination an excellent choice for the first-line treatment regimen for mRCC. These combinations have proven to be tolerable, though long-term results are still lacking. As treatment options for $\mathrm{mRCC}$ are rapidly expanding, immunotherapy combinations could potentially change the treatment paradigm, with the ultimate goal of prolonging life and eventually curing $\mathrm{mRCC}$.
\end{abstract}

Keywords: pembrolizumab, axitinib, renal cell carcinoma

\section{Introduction}

Each year worldwide, renal cell carcinoma (RCC) affects more than 393,000 people and leads to 139,000 deaths. The United States has approximately 73,750 new cases and 14,830 deaths annually from $\mathrm{RCC}^{1}$, with increasing incidence related to obesity $^{2}$ and smoking. ${ }^{3}$

RCC can be idiopathic or hereditary; people with a family history of RCC tend to have a risk of developing RCC of less than $1: 114(0.07 \%) .{ }^{4}$ The major histologic subtypes per World Health Organization classification are clear cell RCC (ccRCC) and non-clear cell RCC (nccRCC), which includes papillary, chromophobe, collecting duct tumors, other rarer molecular subcategories, and an unclassified category. 
At initial presentation, approximately $19 \%$ of RCC patients either have advanced locoregional disease (stage III; $8 \%$ ) or distant metastases (stage IV; $11 \%$ ). ${ }^{5}$ While surgery is the only curative option for early-stage disease, cytoreductive nephrectomy can be considered for mRCC patients who have a long-term sustained benefit from systemic therapy, though the CARMENA ${ }^{6,7}$ and SURTIME $^{8}$ trials suggest that systemic therapy should be prioritized. Also, a subset of patients with slow-growing oligometastatic RCC with a prolonged time interval from removal of primary tumor to metastases development can safely be surveilled before starting systemic therapy, as reported by Rini et al. ${ }^{9}$ In those patients, metastasectomy could also be considered since it is associated with survival benefit in the era of targeted therapy. ${ }^{10}$

\section{Vascular Endothelial Growth Factor Antibodies and Mammalian Target of Rapamycin Inhibitors as First-Line Therapy in $\mathrm{mRCC}$}

Over the last few decades, several drugs have been approved as first-line therapy to treat patients with mRCC, including vascular endothelial growth factor (VEGF) antibodies, tyrosine kinase inhibitors (TKIs), and agents targeting the mammalian target of rapamycin $(\mathrm{mTOR})^{11}$ (as summarized in Table 1).

In 2005, sorafenib became the first TKI approved by the US Food and Drug Administration (FDA) for the treatment of mRCC, based on a phase III trial that randomized mRCC patients to sorafenib or placebo. ${ }^{12}$ The median progression-free survival (PFS) with sorafenib was 5.5 months vs 2.8 months with placebo (hazard ratio [HR] $=0.44,95 \%$ confidence interval $[\mathrm{CI}] 0.35-0.55 ; \mathrm{p}<0.01$ ). Although overall survival (OS) also favored sorafenib over placebo (HR=0.72, 95\% CI 0.54-0.94; $\mathrm{p}=0.02)$, this benefit was not statistically significant per predefined statistical parameters. The most common side effects, among others, were palmar-plantar erythrodysesthesia, diarrhea, rash, and fatigue. Although sorafenib is FDA-approved, it is not commonly used since it is less tolerable than sunitinib and pazopanib.

Sunitinib, a multikinase inhibitor of the VEGF receptor (VEGFR), c-Kit and platelet-derived growth factor receptor (PDGFR), was FDA-approved for treatment of mRCC in 2006 and has been the standard of care in subsequent mRCC clinical trials. ${ }^{13}$ In a phase III study comparing sunitinib and interferon-alfa $(\mathrm{IFN}-\alpha)$, patients treated
Table I Front-Line Therapies Targeting VEGF and mTOR Pathways in $\mathrm{mRCC}$

\begin{tabular}{|l|l|l|}
\hline Drug & Advantages & Disadvantages \\
\hline Sorafenib & $\begin{array}{l}\text { Improves PFS (5.5 vs 2.8 } \\
\text { months) }\end{array}$ & $\begin{array}{l}\text { Less tolerable than } \\
\text { sunitinib or } \\
\text { pazopanib }\end{array}$ \\
\hline Sunitinib & $\begin{array}{l}\text { Improves PFS (II vs 5 } \\
\text { months) } \\
\text { Good ORR 47\% }\end{array}$ & Lack of OS benefit \\
\hline Temsirolimus & $\begin{array}{l}\text { Improves OS (10.9 vs 7.3 } \\
\text { months) } \\
\text { Good option for intermediate- } \\
\text { to poor-risk mRCC and non- } \\
\text { clear cell histology }\end{array}$ & $\begin{array}{l}\text { Weekly IV dosing } \\
\text { responses by } \\
\text { RECIST criteria }\end{array}$ \\
\hline $\begin{array}{l}\text { Bevacizumab } \\
+ \text { IFN- } \alpha\end{array}$ & $\begin{array}{l}\text { Improves PFS (I0.2 vs 5.4 } \\
\text { months) }\end{array}$ & $\begin{array}{l}\text { IFN- } \alpha \text { is not well- } \\
\text { tolerated } \\
\text { No OS benefit }\end{array}$ \\
\hline Pazopanib & $\begin{array}{l}\text { Improves PFS (9.2 vs 4.2 } \\
\text { months) } \\
\text { Noninferior to sunitinib } \\
\text { (COMPARZ) }\end{array}$ & $\begin{array}{l}\text { Higher incidence of } \\
\text { hepatotoxicity }\end{array}$ \\
\hline Cabozantinib & $\begin{array}{l}\text { Improves PFS (8.6 vs 5.3 } \\
\text { months) }\end{array}$ & $\begin{array}{l}\text { Not an option for } \\
\text { good-risk mRCC }\end{array}$ \\
\hline
\end{tabular}

Abbreviations: VEGF, vascular endothelial growth factor; mTOR, mammalian target of rapamycin; mRCC, metastatic renal cell carcinoma; OS, overall survival; PFS, progression-free survival; ORR, overall response rate; IFN- $\alpha$, interferon-alpha.

with sunitinib had significantly longer PFS (11 months vs 5 months) (HR=0.42, 95\% CI 0.32-0.54; $\mathrm{p}<0.001) .{ }^{14}$ When results were updated, there was a trend toward improved OS in the sunitinib group (26.4 vs 21.8 months, respectively; HR $=0.821,95 \%$ CI $0.673-1.001 ; \mathrm{p}=0.051) .{ }^{15}$ Overall response rate (ORR) for sunitinib was $47 \%$ compared to $12 \%$ for IFN- $\alpha(\mathrm{p}<0.001) .{ }^{16}$ Sunitinib is generally well tolerated; hypertension, nausea, fatigue, and diarrhea are the most common adverse events (AEs).

Temsirolimus, an inhibitor of mTOR, was FDAapproved in 2007 for first-line treatment of intermediateto poor-risk mRCC, including nccRCC. In a phase III trial, 626 patients with untreated $\mathrm{mRCC}$ were randomized to one of the 3 arms: combination of temsirolimus $15 \mathrm{mg}$ weekly and IFN- $\alpha 3 \mathrm{x} /$ week, temsirolimus $25 \mathrm{mg}$ i.v. weekly, or IFN- $\alpha 3$ MIU s.c. $3 x /$ week. ${ }^{17}$ Median OS was 10.9 months for temsirolimus monotherapy, 7.3 months for IFN- $\alpha$, and 8.4 months for the combination therapy. Temsirolimus yielded more hyperglycemia, rash, hyperlipidemia, and peripheral edema. Interestingly, improvement 
in OS was most pronounced in patients with non-clear-cell histology $(\mathrm{n}=73){ }^{18}$

In 2009, the FDA-approved bevacizumab in combination with IFN- $\alpha$ for first-line treatment of mRCC. In a phase III trial (AVOREN), 649 patients were randomized: 327 were treated with bevacizumab $10 \mathrm{mg} / \mathrm{kg}$ i.v. every 2 weeks plus IFN- $\alpha$-2a 9 MIU s.c. $3 x /$ week, while 322 received placebo plus IFN- $\alpha-2 a{ }^{19}$ The primary endpoint, median PFS, was longer in the bevacizumab plus IFN- $\alpha$-2a group (10.2 months vs 5.4 months; $H R=0.63$, $95 \%$ CI $0.52-0.75 ; \mathrm{p}=0.0001)$, irrespective of risk category. The most commonly reported grade $\geq 3$ AEs were fatigue $(12 \%)$ and asthenia $(10 \%)$. Unfortunately, in a follow-up report, there was no significant difference in median OS between the 2 arms. $^{20}$

Pazopanib, a multikinase inhibitor of VEGFR-1, -2, and -3 , PDGFR- $\alpha$ and $-\beta$, and c-KIT, was FDA-approved for treatment of $\mathrm{mRCC}$ in 2009. In a phase III trial, pazopanib increased PFS over placebo (9.2 months vs 4.2 months, respectively; $\mathrm{HR}=0.46$, 95\% CI $0.34-0.62$; $\mathrm{p}<0.0001) .^{21}$ Pazopanib had an ORR of $30 \%$ vs $3 \%$ for placebo $(\mathrm{p}<0.001)$. Common AEs included anorexia, nausea, vomiting, diarrhea, hypertension, and changes in hair color. A large phase III study (COMPARZ) comparing sunitinib to pazopanib found similar clinical outcomes for each, although quality of life and toxicity profile favored pazopanib. ${ }^{22}$

Cabozantinib, a multikinase inhibitor of VEGFRs, MET, and AXL, was FDA-approved in 2017 as first-line treatment for $\mathrm{mRCC}$ based on the results of the CABOSUN trial. In this phase II study, patients with intermediate- or poor-risk $\mathrm{mRCC}$ were randomized to cabozantinib or sunitinib. ${ }^{23-25}$ Median PFS was improved at 8.6 months for cabozantinib (95\% CI 6.8-14.0) compared to 5.3 months for sunitinib (95\% CI 3.0-8.2) ( $\mathrm{HR}=0.48$, 95\% CI 0.31-0.74; $\mathrm{p}=0.0008)$. ORR for cabozantinib was $20 \%$ vs $9 \%$ for sunitinib. Common side effects with cabozantinib are hypertension (28\%), diarrhea $(10 \%)$, palmar-plantar erythrodysesthesia $(8 \%)$, fatigue $(6 \%)$, and hematologic toxicities $(3 \%){ }^{18}$

\section{Immunotherapy as First-Line Treatment for $\mathrm{mRCC}$}

Before the advent of the immune checkpoint inhibitors in the last 5 years, the first immunotherapy agent for ccRCC was a cytokine, high-dose interleukin (IL)-2, approved in 1992 due to its ability to cure a small subset of mRCC patients. $^{26,27}$
McDermott et al reported superior survival with high-dose IL-2 compared to s.c. IL-2 plus IFN- $\alpha-2 b$ for patients with primary tumor in situ $(\mathrm{p}=0.040)$ or with liver or bone metastases $(\mathrm{p}=0.001) .^{28}$ Interestingly, a durable complete response (CR) was observed in 5-9\% of patients. ${ }^{27,29}$ The most common side effects were capillary leak syndrome, urinary tract and catheter-site infections, hypotension, tachycardia, dyspnea, renal dysfunction, hyperbilirubinemia, transaminase elevations, and neurological changes, ${ }^{30}$ leading to death in $4 \%$ of patients in the initial studies. ${ }^{26}$ A recently published retrospective analysis of 170 patients treated with high-dose IL-2 from 2005 to 2012 using the PROCLAIM registry showed that duration of median OS was longer than historically reported (median OS for treatment-naïve patients was 48.9 months) and that high-dose IL-2 can be administered safely and still has a role in the treatment of eligible patients. ${ }^{31}$ Moreover, according to National Comprehensive Cancer Network (NCCN) Guidelines, high-dose IL-2 is still recommended for first-line treatment of favorable-risk ccRCC in patients with excellent Karnofsky performance status (KPS) and normal organ function. ${ }^{18}$

From their initial discovery, immune checkpoint inhibitors have been studied extensively, since metastatic kidney cancer is considered immunogenic due to the increased infiltration of different immune cells such as $\mathrm{T}$ cells and NK cells. ${ }^{32}$ However, regulatory $\mathrm{T}$ cells (Tregs), tumor-associated macrophages, and myeloidderived suppressor cells (MDSCs) are responsible for immunosuppression frequently observed in mRCC. ${ }^{33}$ In addition to immunosuppressive cells, increased levels of pro-inflammatory cytokines such as TNF- $\alpha$, IL-6, and interleukin-1 beta (IL-1 $\beta$ ) are also associated with worse prognosis and advanced disease. ${ }^{34}$ Anti-PD-1 and antiCTLA4 antibodies improve T-cell responses and allow upregulation of anticancer activity by negative Treg regulation and increased IFN- $\gamma$ and IL-2 production. One of the key mechanisms of resistance to immune checkpoint inhibitors is MDSCs, ${ }^{35}$ which are known to accumulate in kidney tumors and inhibit activation of CD4+ and CD8+ T cells. ${ }^{36}$

Pembrolizumab, a selective, fully humanized immunoglobulin G4- $\kappa$ monoclonal antibody against PD-1, is FDAapproved for the treatment of many cancers, including head and neck squamous cell carcinoma, melanoma, non-small cell and small cell lung cancer, gastric cancer, urothelial cancer, triple-negative breast cancer, microsatellite instability-high (MSI-high) colorectal cancer, and Hodgkin lymphoma. ${ }^{37,38}$ Pembrolizumab was also approved in 2017 
for the treatment of mismatch repair-deficient or MSI-high solid tumors, which was the first tissue-agnostic approval in oncology. $^{38}$

KEYNOTE-427 was an single arm, open-label, phase II trial to evaluate pembrolizumab as first-line treatment for ccRCC (cohort A). ${ }^{39,40}$ The primary endpoint was ORR, which was reported to be $33.6 \%$ (95\% CI $24.8-$ 43.4), with $1 \mathrm{CR}$ and 35 partial responses (PRs). ${ }^{39}$ Updated results showed that ORR was 36.4\%, with 37 PRs and 3 CRs. ${ }^{40}$ Median duration of response (DOR) and median OS were not reached. Median PFS was 7.1 months (95\% CI 5.6-11.0). The toxicity profile was consistent with previous experiences. Grade 3-5 treatmentrelated adverse events (TRAEs) occurred in $73.6 \%$ of patients, including fatigue $(23.6 \%)$, pruritis $(21.8 \%)$, diarrhea $(16.4 \%)$, rash $(13.6 \%)$, and arthralgia (11.8\%).

In cohort B of KEYNOTE-427, 165 patients with nccRCC were treated with pembrolizumab $200 \mathrm{mg}$ i.v. every 3 weeks for up to 35 cycles. ${ }^{41}$ The primary endpoint was ORR. Within this cohort, $68 \%$ of patients had intermediate- to poor-risk disease per International Metastatic RCC Database Consortium (IMDC) criteria, and 62\% had PD-L1-positive disease. ORR was 24.8\% (95\% CI 18.532.2); median DOR was not reached. By histology, ORR was $25.4 \%$ (95\% CI 17.9-34.3) for papillary, 9.5\% (95\% CI 1.2-30.4) for chromophobe, and 34.6\% (95\% CI 17.2-55.7) for unclassified nccRCC. ORR was $28.3 \%(95 \%$ CI 16.8-42.3) for patients with favorable-risk disease vs $23.3 \%$ (95\% CI 15.8-32.1) for patients with intermediateto poor-risk disease. TRAEs occurred in $11 \%$ of patients and led to a discontinuation rate of $6 \%$. As with cohort $\mathrm{A}$, the full results of cohort $\mathrm{B}$ have not been published. Pembrolizumab monotherapy is not currently FDAapproved for the treatment of mRCC. ${ }^{18}$

Nivolumab, a programmed cell death protein 1 (PD-1) inhibitor, was FDA-approved in 2015 as second-line treatment of metastatic kidney cancer after treatment with a VEGF-targeting agent, based on the results of the CheckMate 025 study which showed improved OS in patients treated with nivolumab (25 months) compared to everolimus. Nivolumab monotherapy is not approved as first-line mRCC treatment.

The combination of nivolumab ( $3 \mathrm{mg} / \mathrm{kg}$ ) plus ipilimu$\mathrm{mab}(1 \mathrm{mg} / \mathrm{kg})$ was studied as first-line therapy in a phase III trial (CheckMate 214). ${ }^{42}$ At the 18 -month point, OS was $75 \%$ vs $60 \%$ for nivolumab/ipilimumab compared to sunitinib, respectively. The median OS was not reached in the nivolumab/ipilimumab group vs 26.0 months with sunitinib $(\mathrm{HR}=0.63 ; \mathrm{p}<0.001)$. In an extended follow-up study, nivolumab/ipilimumab continued to be better than sunitinib in terms of OS (median OS not reached [95\% CI 35.6-not estimable] vs 26.6 months [95\% CI 22.1-33.4]; $\mathrm{HR}=0.66,95 \% \mathrm{CI} 0.54-0.80 ; \mathrm{p}<0.0001)$ and the fraction of patients achieving an objective response (42\% vs $29 \%$; $\mathrm{p}=0.0001) .^{43}$ Discontinuation due to TRAEs occurred in $22 \%$ of the nivolumab/ipilimumab group vs $12 \%$ of the sunitinib group. Of patients with TRAEs in the nivolumab/ ipilimumab group, 35\% received high-dose glucocorticoids ( $\geq 40 \mathrm{mg}$ of prednisone per day or equivalent). This immunotherapy combination is not ideal for good-risk mRCC patients since the risk of serious toxicity outweighs potential treatment benefits. TRAEs in the nivolumab/ipilimumab group were observed in $93 \%$ of patients, including immune-related AEs such as pruritis, rash, and lipase elevation. In 2018 this pivotal trial led to FDA approval of the nivolumab/ipilimumab combination for intermediateand poor-risk treatment naïve $\mathrm{mRCC}$ patients. ${ }^{18}$

\section{Combination of VEGF-Targeted Therapy and Immune Checkpoint Inhibitors as First-Line Treatment for CCRCC}

Most patients treated with VEGFR inhibitors will eventually develop resistance to therapy. In preclinical models, resistance to antiangiogenic therapy is mediated through a variety of mechanisms: ${ }^{44} 1$ ) production of redundant and alternative angiogenic factors by tumor cells; 2) induction of hypoxia, which in turn upregulates HIF-1 and leads to transcription of proangiogenic genes; 3) mobilization of bone marrow-derived proangiogenic cells, including endothelial and pericyte progenitors, tumor-associated macrophages, immature monocytic cells, and myeloid cells; and 4) the formation of collateral circulation. Additional preclinical evidence suggests that tumor vasculature is an important barrier to $\mathrm{T}$ cells. ${ }^{45}$ Angiogenesis inhibition can increase T-cell infiltration and enhance antitumor activity by decreasing the effect of macrophages and MDSCs. In a murine model of colon adenocarcinoma, treatment with anti-VEGFR-2 and anti-PD-1 monoclonal antibodies simultaneously inhibited tumor growth synergistically in vivo. Specifically, combining anti-PD-1 and anti-VEGFR-2 therapy increased the number of infiltrating $\mathrm{CD}^{+}$and $\mathrm{CD}^{+}{ }^{\mathrm{T}}$ cells. ${ }^{46}$ These findings suggest that the combination of anti-VEGF and anti-PD-1 therapies may 
have immune-modulating functions and clinical benefits greater than either modality alone.

The combination of anti-VEGF and anti-PD-1 therapy was tested in multiple trials with variable success. CheckMate 016 was an open-label phase I study that examined the efficacy and safety of nivolumab combined with sunitinib or pazopanib. ${ }^{47,48}$ The nivolumab plus sunitinib arm had high incidence of AEs (TRAEs in 100\% of patients), making this combination too toxic for further development. Another phase I/II study tested the combination of pembrolizumab and pazopanib, but this combination was also not further developed due to dose-limiting hepatotoxicity. ${ }^{49}$ It was thought that observed toxicities were related to off-target effects of the TKIs and that a more selective VEGF inhibitor, such as axitinib, may be better tolerated. Axitinib was a clear choice since it is a second-generation multikinase receptor inhibitor of VEGFR-1, -2 , and $-3^{50}$ and is already approved as second-line therapy for $\mathrm{mRCC}$ as monotherapy. ${ }^{51}$

\section{Avelumab Plus Axitinib}

The JAVELIN Renal 100 trial was an open-label, multicenter, phase $\mathrm{Ib}$ trial $^{52}$ that tested the combination of axitinib $5 \mathrm{mg}$ p.o. twice daily for a lead-in of 7 days, followed by combined avelumab $10 \mathrm{mg} / \mathrm{kg}$ i.v. every 2 weeks and axitinib $5 \mathrm{mg}$ p.o. twice daily. At the data cutoff date, $100 \%$ of patients $(6 / 6)$ in the dose-finding cohort and $53 \%$ of patients $(26 / 49)$ in the dose-expansion cohort had confirmed objective responses $(58 \%$; 32/55 total patients). Promising results from this study led to a phase III study (JAVELIN Renal 101). ${ }^{53}$ Patients were randomized to avelumab $10 \mathrm{mg} / \mathrm{kg}$ i.v. every 2 weeks plus axitinib $5 \mathrm{mg}$ p.o. twice daily or sunitinib $50 \mathrm{mg}$ p.o. daily. Median PFS was 13.8 months vs 7.2 months favoring the avelumab/axitinib group $(\mathrm{HR}=0.61 ; 95 \%$ CI $0.47-0.79$; $\mathrm{p}<0.001)$. It is important to note that although this study met its primary endpoint for PFS, OS was not statistically significant. The main secondary endpoint was PFS in the overall population, which was 13.8 months for the avelumab/axitinib group and 8.4 months for the sunitinib group $(\mathrm{HR}=0.69$, 95\% CI 0.56-0.84; $\mathrm{p}<0.001)$. Grade $\geq 3$ AEs were observed in $71.2 \%$ of patients in the avelumab/axitinib group compared to $71.5 \%$ in the control group. The most common AEs were diarrhea (62.2\% vs 47.6\%, respectively) and hypertension $(49.5 \%$ vs $36.0 \%$, respectively). For patients in the avelumab/axitinib group, 38.2\% experienced immune-related AEs and $9.0 \%$ had grade $\geq 3$ AEs. High-dose glucocorticoids ( $\geq 40 \mathrm{mg}$ of prednisone per day or equivalent) were given to $11.1 \%$ of patients who received avelumab/axitinib. Based on the results of this trial, the FDA approved this combination for first-line treatment of ccRCC in 2019.

\section{Atezolizumab Plus Bevacizumab}

In a multicenter, open-label, phase III trial (IMmotion 151), patients with ccRCC or sarcomatoid histology were randomized to atezolizumab $1200 \mathrm{mg}$ and bevacizumab $15 \mathrm{mg} / \mathrm{kg}$ i.v. every 3 weeks or sunitinib $50 \mathrm{mg}$ p.o. daily for 4 weeks on and 2 weeks off. ${ }^{54}$ The study met the coprimary endpoints of PFS in patients with PD-L1+ disease and OS in the intention-to-treat population. Median PFS was 11.2 months with atezolizumab/bevacizumab and 7.7 months with sunitinib (stratified $\mathrm{HR}=0.74$, 95\% CI $0.57-$ 0.96; $\mathrm{p}=0.0217$ ). In the intention-to-treat population, OS was not significantly different between the 2 groups. Atezolizumab/bevacizumab group had fewer grade 3-4 TRAEs than patients in the sunitinib group (40\% vs $56 \%$, respectively), and fewer patients discontinued therapy due to TRAEs ( $5 \%$ vs $8 \%$, respectively). ${ }^{54}$ The most common grade 3 or 4 TRAE in the atezolizumab/bevacizumab group was hypertension (14\%). In the sunitinib group, the most common side effects were hypertension (17\%) and palmar-plantar erythrodysesthesia (9\%). Interestingly, observed immune-related AEs, including hypothyroidism, rash, and liver function test abnormalities, were low-grade. Of patients receiving atezolizumab/ bevacizumab, 9\% received high-dose glucocorticoids.

\section{Pembrolizumab Plus Axitinib}

In an open-label phase $1 \mathrm{~b}$ trial testing the combination of pembrolizumab $2 \mathrm{mg} / \mathrm{kg}$ i.v. every 3 weeks and axitinib $5 \mathrm{mg}$ p.o. twice daily in patients with advanced RCC (predominantly clear cell type), 73\% of patients achieved either a CR or PR with acceptable toxicity. ${ }^{55}$ This led to KEYNOTE-426, a pivotal open-label, phase III trial in which 861 patients with ccRCC were randomized to receive pembrolizumab/axitinib (pembrolizumab $200 \mathrm{mg}$ i.v. every 3 weeks plus axitinib $5 \mathrm{mg}$ p.o. twice daily) or sunitinib (50 mg p.o. daily, 4 weeks on and 2 off). ${ }^{56}$ Eligible patients had recurrent or newly diagnosed stage IV ccRCC, were 18 years and older, were treatment-naïve, had a KPS score of $\geq 70 \%$, and had measurable disease and tumor tissue available for biomarker analysis. Exclusion criteria included history of autoimmune disease, CNS metastases, uncontrolled hypertension ( $\geq 150 / 90 \mathrm{mmHg}$ ), cardiovascular ischemic disease, New York Heart 
Association class III or IV congestive heart failure diagnosed within 1 year before screening, or current systemic immunosuppressive therapy. Patients were stratified by IMDC risk groups, including favorable, intermediate, or poor risk. The median duration of treatment was 10.4 months in the pembrolizumab/axitinib group and 7.8 months in the sunitinib group. Disease progression was the most common reason for discontinuation. Dual primary outcomes of OS and PFS favored the pembrolizumab/axitinib group. At 12 months, $89.9 \%$ of patients $(95 \%$ CI 86.4-92.4) were alive in the pembrolizumab/axitinib group vs $78.3 \%$ of patients (95\% CI $73.8-82.1)$ in the sunitinib group. The pembrolizumab/axitinib group had a $47 \%$ lower risk of death compared to the sunitinib group (HR $=0.53 ; 95 \%$ CI $0.38-0.74 ; \mathrm{p}<0.0001)$. At 18 months, $82.3 \%$ of patients $(95 \%$ CI $77.2-86.3)$ were alive in the pembrolizumab/axitinib group vs $72.1 \%$ of patients (95\% CI 66.3-77.0) in the sunitinib group. Median PFS was also significantly longer (15.1 months in the pembrolizumab/axitinib group vs 11.1 months in the sunitinib group; HR for disease progression or death $=0.69$; 95\% CI $0.57-0.84 ; \mathrm{p}<0.001)$. Interestingly, the improved OS and PFS were seen in all IMDC risk groups and in all PD-L1 expression categories. The secondary outcome of ORR also favored the pembrolizumab/axitinib group (59.3\%) over the sunitinib group $(35.7 \%$; $95 \%$ CI $31.1-$ $40.4 ; \mathrm{p}<0.001)$. Median DOR was not reached in the pembrolizumab/axitinib group (1.4-18.2 months) and was 15.2 months (1.1-15.4) in the sunitinib group. These intriguing data demonstrated that the combination of pembrolizumab and axitinib could be used as first-line treatment for ccRCC.

In the KEYNOTE-426 trial, $98.4 \%$ of patients in the pembrolizumab/axitinib group experienced an $\mathrm{AE}$ vs $99.5 \%$ of patients in the sunitinib group. ${ }^{56}$ Grade $\geq 3$ TRAEs were noted in $62.9 \%$ of patients in the pembrolizumab/axitinib group vs $58.1 \%$ of patients in the sunitinib group. In both groups, the most common AEs were diarrhea and hypertension. Grade $\geq 3$ AEs that occurred in $\geq 10 \%$ of patients were hypertension in the sunitinib group and increased ALT and hypertension in the pembrolizumab/axitinib group. The discontinuation rate for pembrolizumab/axitinib was $10.7 \%$ vs $13.9 \%$ for sunitinib. AEs of interest were observed in 51.3\% of patients given pembrolizumab/axitinib and in $36.2 \%$ of patients treated with sunitinib.

Taken together, results from these trials show that the combination of pembrolizumab and axitinib improves both PFS and OS compared to sunitinib. Also, this combination seems to work in patients with mRCC with sarcomatoid features who historically do not respond well to VEGFand mTOR-targeted therapies. This study led to FDA approval in 2019 of pembrolizumab/axitinib as first-line treatment for ccRCC.

\section{Future Directions and Conclusions}

Immunotherapy has transformed the treatment paradigm for many cancers. The approval of first-line immunotherapy combinations in $\mathrm{mRCC}$ has dramatically changed the role of agents targeting the VEGF and mTOR pathways. Multiple research groups are actively seeking more effective treatments for $\mathrm{mRCC}$, as evidenced by 321 clinical trials listed at ClinicalTrials.gov as of February 10, 2020, ${ }^{57}$ several of them testing combinations of anti-VEGF therapy and immune checkpoint inhibitors (Table 2). Three recently approved immunotherapeutic first-line combination treatments for $\mathrm{mRCC}$ have substantially improved treatment options for patients with RCC. Still, several issues remain to be addressed, including appropriate patient selection, side-effect monitoring, and biomarker development to determine who will benefit the most from immunotherapy treatment combinations.

One of the most difficult challenges for a practicing clinician is choosing among approved therapies in the first-line setting (Figure 1). We believe that all $\mathrm{mRCC}$ patients with no contraindications to immunotherapy should receive an immunotherapy-based regimen as first-line treatment. Patients with excellent organ function and no comorbidities can be considered for high-dose IL-2, and responses may be assessed quickly. For mRCC patients with favorable-risk disease, axitinib plus pembrolizumab is the preferred treatment option because this combination improves OS and has an acceptable toxicity profile. For patients who are not candidates for immunotherapy, sunitinib or pazopanib are still considered treatments of choice.

For intermediate/poor-risk disease, the situation is more complicated since both nivolumab/ipilimumab and axitinib/ pembrolizumab are good choices. Axitinib/pembrolizumab may be a superior option given its toxicity profile (lower discontinuation rate than for nivolumab/ipilimumab), but these two combination therapies have not been compared directly. Some axitinib and pembrolizumab toxicities may be overlapping, although caused by a different mechanism (eg, diarrhea or liver function test abnormalities). However, management is easier with axitinib as one can hold the drug for a few days to see if toxicity improves before starting 
Table 2 Ongoing Phase III Clinical Trials Combining Checkpoint Inhibitors and Anti-VEGF Therapy

\begin{tabular}{|c|c|c|c|c|c|}
\hline Phase & Title & $\begin{array}{l}\text { NCT } \\
\text { Number }\end{array}$ & Status & $\begin{array}{l}\text { Patients } \\
\text { (n) }\end{array}$ & Primary Endpoint(s) \\
\hline $\begin{array}{l}\text { Phase III, multicenter, } \\
\text { randomized, open- } \\
\text { label }\end{array}$ & $\begin{array}{l}\text { Study of Nivolumab Combined with } \\
\text { Cabozantinib Compared to Sunitinib } \\
\text { in Previously Untreated Advanced } \\
\text { or Metastatic RCC (CheckMate } \\
\text { 9ER) }\end{array}$ & NCT03।4II77 & $\begin{array}{l}\text { Active, } \\
\text { not } \\
\text { recruiting }\end{array}$ & 701 & PFS per blinded independent review \\
\hline $\begin{array}{l}\text { Phase III, multicenter, } \\
\text { randomized, double- } \\
\text { blinded }\end{array}$ & $\begin{array}{l}\text { Study of Cabozantinib with } \\
\text { Nivolumab and Ipilimumab in } \\
\text { Patients with Previously Untreated } \\
\text { Advanced or Metastatic RCC } \\
\text { (COSMIC-3/3) }\end{array}$ & NCT03937219 & Recruiting & 676 & PFS per blinded independent review \\
\hline $\begin{array}{l}\text { Phase III, multicenter, } \\
\text { randomized, open- } \\
\text { label }\end{array}$ & $\begin{array}{l}\text { Immunotherapy with Nivolumab } \\
\text { and Ipilimumab Followed by } \\
\text { Nivolumab or Nivolumab with } \\
\text { Cabozantinib for Patients with } \\
\text { Advanced Kidney Cancer }\end{array}$ & NCT03793I66 & Recruiting & 1046 & OS \\
\hline $\begin{array}{l}\text { Phase III, multicenter, } \\
\text { randomized, open- } \\
\text { label }\end{array}$ & $\begin{array}{l}\text { Lenvatinib/Everolimus or Lenvatinib/ } \\
\text { Pembrolizumab versus Sunitinib } \\
\text { Alone as Treatment of Advanced } \\
\text { Renal Cell Carcinoma (CLEAR) }\end{array}$ & NCT028II86I & $\begin{array}{l}\text { Active, } \\
\text { not } \\
\text { recruiting }\end{array}$ & 1069 & PFS per independent review \\
\hline $\begin{array}{l}\text { Phase III, randomized, } \\
\text { open-label }\end{array}$ & $\begin{array}{l}\text { Study to Evaluate the Efficacy and } \\
\text { Safety of Pembrolizumab (MK-3475) } \\
\text { in Combination with Axitinib versus } \\
\text { Sunitinib Monotherapy in } \\
\text { Participants with RCC (MK-3475- } \\
\text { 426/KEYNOTE-426) }\end{array}$ & NCT0285333I & $\begin{array}{l}\text { Active, } \\
\text { not } \\
\text { recruiting }\end{array}$ & 861 & $\begin{array}{l}\text { PFS per blinded independent review } \\
\text { and OS }\end{array}$ \\
\hline $\begin{array}{l}\text { Phase III, multicenter, } \\
\text { randomized, open- } \\
\text { label }\end{array}$ & $\begin{array}{l}\text { A Study of Atezolizumab in } \\
\text { Combination with Bevacizumab } \\
\text { versus Sunitinib in Participants with } \\
\text { Untreated Advanced RCC } \\
\text { (IMmotion I5I) }\end{array}$ & NCT0242082I & $\begin{array}{l}\text { Active, } \\
\text { not } \\
\text { recruiting }\end{array}$ & 915 & $\begin{array}{l}\text { Percentage of participants with } \\
\text { disease progression or death from } \\
\text { any cause; PFS in PD-LI selected } \\
\text { population; percentage of } \\
\text { participants who died of any cause } \\
\text { in ITT population; and OS in ITT } \\
\text { population }\end{array}$ \\
\hline $\begin{array}{l}\text { Phase III, multicenter, } \\
\text { randomized, open- } \\
\text { label }\end{array}$ & $\begin{array}{l}\text { Study of Avelumab with Axitinib } \\
\text { versus Sunitinib in Advanced RCC } \\
\text { (JAVELIN Renal I0I) }\end{array}$ & NCT02684006 & $\begin{array}{l}\text { Active, } \\
\text { not } \\
\text { recruiting }\end{array}$ & 886 & $\begin{array}{l}\mathrm{PFS} \text { and } \mathrm{OS} \text { in PD-LI-positive } \\
\text { patients }\end{array}$ \\
\hline
\end{tabular}

Abbreviations: ITT, intention to treat; PD-LI, programmed death-ligand I; PFS, progression-free survival; NCT, National Clinical Trial; OS, overall survival; RCC, renal cell carcinoma.

steroids, while with the nivolumab/ipilimumab combination both drugs have to be discontinued.

For second-line therapy in patients with metastatic ccRCC, we again prefer immunotherapy if not previously received. Nivolumab improves OS compared to everolimus, but patients would need to be monitored for immunerelated AEs. For those who have already received immunotherapy, cabozantinib or other TKIs can be considered, while recognizing that these agents may not necessarily invoke a significant response.

Additional trials are needed to address therapy sequencing and should include patients with nccRCC as it is essential that we help these patients find an appropriate clinical trial. Alternatively, first-line agents such as sunitinib, temsirolimus, or pazopanib can be considered. Second-line agents include pembrolizumab or other agents that have not 


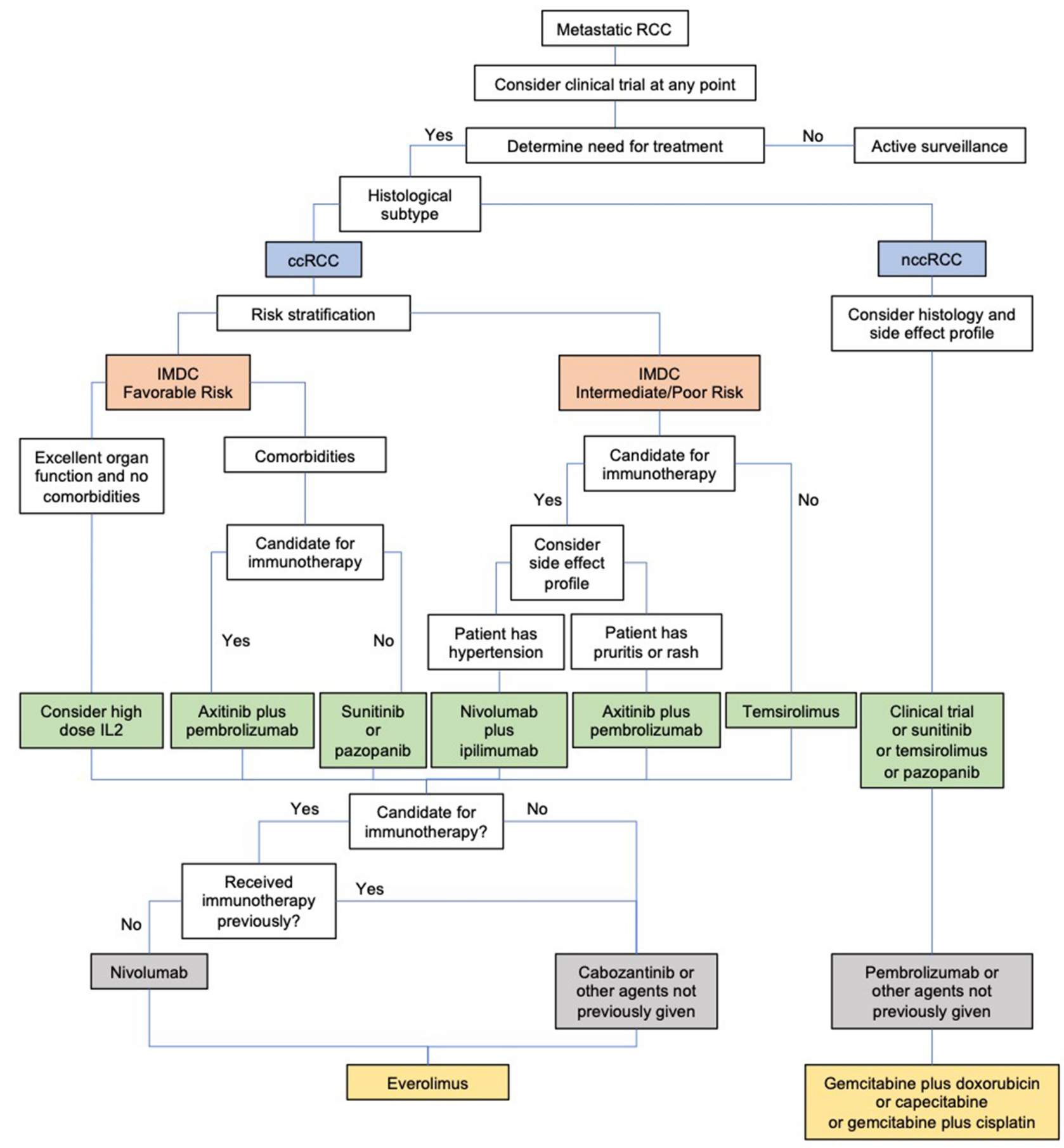

Figure I Proposed algorithm for determining treatment for $\mathrm{mRCC}$.

been previously given. Other than pembrolizumab, immunotherapy remains relatively unexplored in nccRCC.

The rate at which treatments are being developed for RCC is impressive and accelerating.

Overall, combining specific anti-VEGF therapy with immunotherapy is an important strategy for improving survival in patients with $\mathrm{mRCC}$.

\section{Acknowledgments}

The authors acknowledge Kathryn Cappell, MD, PhD for helpful suggestions during the preparation of this manuscript and Bonnie L. Casey for editorial assistance.

\section{Disclosure}

The authors report no conflicts of interest in this work. 


\section{References}

1. Siegel RL, Miller KD, Jemal A. Cancer statistics, 2020. CA Cancer J Clin. 2020;70(1):7-30. doi:10.3322/caac.21590

2. Hakimi AA, Furberg H, Zabor EC, et al. An epidemiologic and genomic investigation into the obesity paradox in renal cell carcinoma. $J$ Natl Cancer Inst. 2013;105(24):1862-1870. doi:10.1093/jnci/djt310

3. Tsivian M, Moreira DM, Caso JR, Mouraviev V, Polascik TJ. Cigarette smoking is associated with advanced renal cell carcinoma J Clin Oncol. 2011;29(15):2027-2031. doi:10.1200/jco.2010.30.9484

4. Zbar B, Glenn G, Merino M, et al. Familial renal carcinoma: clinical evaluation, clinical subtypes and risk of renal carcinoma development. J Urol. 2007;177(2):461-465. doi:10.1016/j.juro.2006.09.037

5. Patel HD, Gupta M, Joice GA, et al. Clinical Stage Migration and Survival for Renal Cell Carcinoma in the United States. Eur Urol Oncol. 2019;2(4):343-348. doi:10.1016/j.euo.2018.08.023

6. Mejean A, Thezenas S, Chevreau C, et al. Cytoreductive nephrectomy $(\mathrm{CN})$ in metastatic renal cancer (mRCC): update on Carmena trial with focus on intermediate IMDC-risk population. J Clin Oncol. 2019;37(suppl 15):4508. doi:10.1200/JCO.2019.37.15_suppl.4508

7. Mejean A, Ravaud A, Thezenas S, et al. Sunitinib Alone or after Nephrectomy in Metastatic Renal-Cell Carcinoma. $N$ Engl $J$ Med. 2018;379(5):417-427. doi:10.1056/NEJMoa1803675

8. Bex A, Mulders P, Jewett M, et al. Comparison of Immediate vs Deferred Cytoreductive Nephrectomy in Patients With Synchronous Metastatic Renal Cell Carcinoma Receiving Sunitinib: the SURTIME Randomized Clinical Trial. JAMA Oncol. 2019;5(2):164-170. doi:10.1001/jamaoncol.2018.5543

9. Rini BI, Dorff TB, Elson P, et al. Active surveillance in metastatic renal-cell carcinoma: a prospective, Phase 2 trial. Lancet Oncol. 2016;17(9):1317-1324. doi:10.1016/s1470-2045(16)30196-6

10. Naito S, Kinoshita H, Kondo T, et al. Prognostic factors of patients with metastatic renal cell carcinoma with removed metastases: a multicenter study of 556 patients.. Urology. 2013;82(4):846-851. doi:10.1016/j.urology.2013.06.035

11. Merza H, Bilusic M. Current Management Strategy for Metastatic Renal Cell Carcinoma and Future Directions. Curr Oncol Rep. 2017;19(4):27. doi:10.1007/s11912-017-0583-8

12. Escudier B, Eisen T, Stadler WM, et al. Sorafenib in advanced clear-cell renal-cell carcinoma. $N$ Engl $J$ Med. 2007;356 (2):125-134. doi:10.1056/NEJMoa060655

13. Mena AC, Pulido EG, Guill--n-Ponce C. Understanding the molecular-based mechanism of action of the tyrosine kinase inhibitor: sunitinib. Anticancer Drugs. 2010;21(Suppl 1):S3-S11. doi:10.1097/ 01.cad.0000361534.44052.c5

14. Motzer RJ, Hutson TE, Tomczak P, et al. Sunitinib versus interferon alfa in metastatic renal-cell carcinoma. $N$ Engl $J$ Med. 2007;356 (2):115-124. doi:10.1056/NEJMoa065044

15. Motzer RJ, Hutson TE, Tomczak P, et al. Overall survival and updated results for sunitinib compared with interferon alfa in patients with metastatic renal cell carcinoma. J Clin Oncol. 2009;27 (22):3584-3590. doi:10.1200/jco.2008.20.1293

16. Drugs@FDA: FDA-Approved Drugs. U.S. Food \& Drug Administration. https://www.accessdata.fda.gov/scripts/cder/daf/index.cfm?event=over view.process\&ApplNo=201275. 2006. Accessed 19 Feb 2020 .

17. Hudes G, Carducci M, Tomczak P, et al. Temsirolimus, interferon alfa, or both for advanced renal-cell carcinoma. $N$ Engl $J$ Med. 2007;356(22):2271-2281. doi:10.1056/NEJMoa066838

18. NCCN Guidelines for Treatment of Cancer by Site. National Comprehensive Cancer Network. https://www.ncen.org/profes sionals/physician_gls/default.aspx. 2019. Accessed 20 Apr 2020..

19. Escudier B, Pluzanska A, Koralewski P, et al. Bevacizumab plus interferon alfa-2a for treatment of metastatic renal cell carcinoma: a randomised, double-blind phase III trial. Lancet. 2007;370 (9605):2103-2111. doi:10.1016/s0140-6736(07)61904-7
20. Escudier B, Bellmunt J, Grier S, et al. Phase III trial of bevacizumab plus interferon alfa-2a in patients with metastatic renal cell carcinoma (AVOREN): final analysis of overall survival. J Clin Oncol. 2010;28 (13):2144-2150. doi:10.1200/jco.2009.26.7849

21. Sternberg CN, Davis ID, Mardiak J, et al. Pazopanib in locally advanced or metastatic renal cell carcinoma: results of a randomized phase III trial. J Clin Oncol. 2010;28(6):1061-1068. doi:10.1200/jco.2009.23.9764

22. Motzer RJ, Hutson TE, Reeves J, et al. LBA8 PR - Randomized, Open-Label, Phase III Trial Of Pazopanib Versus Sunitinib In First-Line Treatment Of Patients With Metastatic Renal Cell Carcinoma (MRCC): results of the Comparz Trial. Ann Oncol. 2012;23(supp19):ixe13. doi:10.1016/S0923-7534(20)34325-8

23. Choueiri TK, Halabi S, Sanford BL, et al. Cabozantinib Versus Sunitinib As Initial Targeted Therapy for Patients With Metastatic Renal Cell Carcinoma of Poor or Intermediate Risk: the Alliance A031203 CABOSUN Trial. J Clin Oncol. 2017;35(6):591-597. doi:10.1200/jco.2016.70.7398

24. Choueiri TK, Hessel C, Halabi S, et al. Cabozantinib versus sunitinib as initial therapy for metastatic renal cell carcinoma of intermediate or poor risk (Alliance A031203 CABOSUN randomised trial): progression-free survival by independent review and overall survival update. Eur J Cancer. 2018;94:115-125. doi:10.1016/j.ejca.2018.02.012

25. Choueiri TK, Hessel C, Halabi S, et al. Corrigendum to 'Cabozantinib versus sunitinib as initial therapy for metastatic renal cell carcinoma of intermediate or poor risk (Alliance A031203 CABOSUN randomised trial): progression-free survival by independent review and overall survival update' [Eur J Cancer 94 (May 2018) 115-125]. Eur J Cancer. 2018;103:287. doi:10.1016/j. ejca.2018.09.022

26. Fyfe G, Fisher RI, Rosenberg SA, Sznol M, Parkinson DR, Louie AC. Results of treatment of 255 patients with metastatic renal cell carcinoma who received high-dose recombinant interleukin-2 therapy. J Clin Oncol. 1995;13(3):688-696. doi:10.1200/jco.1995.13.3.688

27. Fisher RI, Rosenberg SA, Sznol M, Parkinson DR, Fyfe G. Highdose aldesleukin in renal cell carcinoma: long-term survival update. Cancer J Sci Am. 1997;3(Suppl 1):S70-S72.

28. McDermott DF, Regan MM, Clark JI, et al. Randomized phase III trial of high-dose interleukin-2 versus subcutaneous interleukin-2 and interferon in patients with metastatic renal cell carcinoma. $J$ Clin Oncol. 2005;23(1):133-141. doi:10.1200/jco.2005.03.206

29. Rosenberg SA, Yang JC, White DE, Steinberg SM. Durability of complete responses in patients with metastatic cancer treated with high-dose interleukin-2: identification of the antigens mediating response. Ann Surg. 1998;228(3):307-319. doi:10.1097/00000658199809000-00004

30. Schwartz RN, Stover L, Dutcher JP. Managing toxicities of high-dose interleukin-2. Oncology. 2002;16(11Suppl 13):11-20.

31. Alva A, Daniels GA, Wong MK, et al. Contemporary experience with high-dose interleukin-2 therapy and impact on survival in patients with metastatic melanoma and metastatic renal cell carcinoma. Cancer Immunol Immunother. 2016;65(12):1533-1544. doi:10.1007/ s00262-016-1910-x

32. Murphy KA, James BR, Guan Y, Torry DS, Wilber A, Griffith TS. Exploiting natural anti-tumor immunity for metastatic renal cell carcinoma. Hum Vaccin Immunother. 2015;11(7):1612-1620. doi:10.1080/21645515.2015.1035849

33. Finke JH, Rayman PA, Ko JS, Bradley JM, Gendler SJ, Cohen PA. Modification of the tumor microenvironment as a novel target of renal cell carcinoma therapeutics. Cancer J. 2013;19(4):353-364. doi:10.1097/PPO.0b013e31829da0ae

34. Yoshida N, Ikemoto S, Narita K, et al. Interleukin-6, tumour necrosis factor alpha and interleukin-1beta in patients with renal cell carcinoma. Br J Cancer. 2002;86(9):1396-1400. doi:10.1038/sj. bjc. 6600257 
35. De Henau O, Rausch M, Winkler D, et al. Overcoming resistance to checkpoint blockade therapy by targeting PI3K 尘 | in myeloid cells. Nature. 2016;539(7629):443-447. doi:10.1038/nature20554

36. Brodaczewska KK, Szczylik C, Kieda C. Immune consequences of anti-angiogenic therapy in renal cell carcinoma. Contemp Oncol. 2018;22(1a):14-22. doi:10.5114/wo.2018.73878

37. Khoja L, Butler MO, Kang SP, Ebbinghaus S, Joshua AM. Pembrolizumab. J Immunother Cancer. 2015;3:36. doi:10.1186/ s40425-015-0078-9

38. Marcus L, Lemery SJ, Keegan P, Pazdur R, Approval Summary: FDA. Pembrolizumab for the Treatment of Microsatellite Instability-High Solid Tumors. Clin Cancer Res. 2019;25 (13):3753-3758. doi:10.1158/1078-0432.Ccr-18-4070

39. McDermott D, Lee J, Szczylik C, et al. Pembrolizumab monotherapy as first-line therapy in advanced clear cell renal cell carcinoma (accRCC): results from cohort A of KEYNOTE-427. J Clin Oncol. 2018;36(suppl 15):4500. doi:10.1200/JCO.2018.36.15_suppl.4500

40. Tykodi SS, Donskov F, Lee J, et al. First-line pembrolizumab (pembro) monotherapy in advanced clear cell renal cell carcinoma (ccRCC): updated results for KEYNOTE-427 cohort A. J Clin Oncol. 2019;37 (suppl15):4570. doi:10.1200/JCO.2019.37.15_suppl.4570

41. McDermott D, Lee J, Ziobro M, et al. First-line pembrolizumab (pembro) monotherapy for advanced non-clear cell renal cell carcinoma (nccRCC): results from KEYNOTE-427 cohort B. J Clin Oncol. 2019;37(supp17):546. doi:10.1200/JCO.2019.37.7_suppl.546

42. Motzer RJ, Tannir NM, McDermott DF, et al. Nivolumab plus Ipilimumab versus Sunitinib in Advanced Renal-Cell Carcinoma. $N$ Engl J Med. 2018;378(14):1277-1290. doi:10.1056/NEJMoa17 12126

43. Motzer RJ, Rini BI, McDermott DF, et al. Nivolumab plus ipilimumab versus sunitinib in first-line treatment for advanced renal cell carcinoma: extended follow-up of efficacy and safety results from a randomised, controlled, Phase 3 trial. Lancet Oncol. 2019;20 (10):1370-1385. doi:10.1016/s1470-2045(19)30413-9

44. Grepin R, Pages G. Molecular mechanisms of resistance to tumour anti-angiogenic strategies. J Oncol. 2010;2010:835680. doi:10.1155/ 2010/835680

45. Lanitis E, Irving M, Coukos G. Targeting the tumor vasculature to enhance T cell activity. Curr Opin Immunol. 2015;33:55-63. doi:10.1016/j.coi.2015.01.011

46. Yasuda S, Sho M, Yamato I, et al. Simultaneous blockade of programmed death 1 and vascular endothelial growth factor receptor 2 (VEGFR2) induces synergistic anti-tumour effect in vivo. Clin Exp Immunol. 2013;172(3):500-506. doi:10.1111/cei.12069

47. Amin A, Plimack ER, Ernstoff MS, et al. Correction to: safety and efficacy of nivolumab in combination with sunitinib or pazopanib in advanced or metastatic renal cell carcinoma: the CheckMate 016 study. J Immunother Cancer. 2019;7(1):73. doi:10.1186/s40425019-0559-3
48. Amin A, Plimack ER, Ernstoff MS, et al. Safety and efficacy of nivolumab in combination with sunitinib or pazopanib in advanced or metastatic renal cell carcinoma: the CheckMate 016 study. $J$ Immunother Cancer. 2018;6(1):109. doi:10.1186/s40425-0180420-0

49. Chowdhury S, McDermott D, Voss MH, et al. A phase I/II study to assess the safety and efficacy of pazopanib (PAZ) and pembrolizumab (PEM) in patients (pts) with advanced renal cell carcinoma (aRCC). J Clin Oncol. 2017;35(suppl 15):4506. doi:10.1200/ JCO.2017.35.15_suppl.4506

50. Escudier B, Gore M. Axitinib for the management of metastatic renal cell carcinoma. Drugs $R$ D. 2011;11(2):113-126. doi:10.2165/ 11591240-000000000-00000

51. Ellis LM, Hicklin DJ. VEGF-targeted therapy: mechanisms of anti-tumour activity. Nat Rev Cancer. 2008;8(8):579-591. doi:10. $1038 / \mathrm{nrc} 2403$

52. Choueiri TK, Larkin J, Oya M, et al. Preliminary results for avelumab plus axitinib as first-line therapy in patients with advanced clear-cell renal-cell carcinoma (JAVELIN Renal 100): an open-label, dose-finding and dose-expansion, phase $1 \mathrm{~b}$ trial. Lancet Oncol. 2018;19(4):451-460. doi:10.1016/s1470-2045(18)30107-4

53. Motzer RJ, Penkov K, Haanen J, et al. Avelumab plus Axitinib versus Sunitinib for Advanced Renal-Cell Carcinoma. $N$ Engl J Med. 2019;380(12):1103-1115. doi:10.1056/NEJMoa1816047

54. Rini BI, Powles T, Atkins MB, et al. Atezolizumab plus bevacizumab versus sunitinib in patients with previously untreated metastatic renal cell carcinoma (IMmotion151): a multicentre, open-label, phase 3, randomised controlled trial. Lancet. 2019;393(10189):2404-2415. doi:10.1016/s0140-6736(19)30723-8

55. Atkins MB, Plimack ER, Puzanov I, et al. Axitinib in combination with pembrolizumab in patients with advanced renal cell cancer: a non-randomised, open-label, dose-finding, and dose-expansion phase 1b trial. Lancet Oncol. 2018;19(3):405-415. doi:10.1016/s14702045(18)30081-0

56. Rini BI, Plimack ER, Stus V, et al. Pembrolizumab plus axitinib versus sunitinib for advanced renal-cell carcinoma. $N$ Engl J Med. 2019;380(12):1116-1127. doi:10.1056/NEJMoa1816714

57. Study of TAK-228 In Patients With Previously Treated Metastatic Renal Cell Carcinoma. https://clinicaltrials.gov/ct2/show/ $\mathrm{NCT} 03097328$ ? recrs $=$ a\& cond $=$ renal + cell + carcinoma\&draw $=$ $2 \&$ rank=1.2020. Accessed 10 Feb 2020 .

\section{Publish your work in this journal}

Cancer Management and Research is an international, peer-reviewed open access journal focusing on cancer research and the optimal use of preventative and integrated treatment interventions to achieve improved outcomes, enhanced survival and quality of life for the cancer patient.
The manuscript management system is completely online and includes a very quick and fair peer-review system, which is all easy to use. Visit http://www.dovepress.com/testimonials.php to read real quotes from published authors. 